\title{
Implementation of a SWOT-AHP methodology for strategic development of a district heating plant in fuzzy environment
}

\section{Ivana Veličkovska}

Mathematical Institute of the Serbian Academy of Sciences and Arts, Belgrade, Serbia https://orcid.org/0000-0001-7692-8436

\begin{abstract}
In this paper, SWOT analysis and fuzzy Analytic Hierarchy Process (FAHP) have been employed to structure and determine the importance of all identified alternatives for developing strategic management in a local district heating plant in Serbia. Weaknesses are identified as drivers of technological slowdown in the plant. The outcome of the prioritization highlights the importance of solving challenges regarding weaknesses by relying on a variety of opportunities that emerge in the environment. The potential of restoring the equipment of the district heating plant is found to be the most important alternative for strategic development.
\end{abstract}

\section{Keywords}

district heating, strategic management, SWOT, AHP, FAHP

\section{Introduction}

Reaching the sustainable energy development goals can be performed in two directions, by promoting renewable energy sources and by using energy efficient technology (Kveselis, Dzenajavičienè, \& Masaitis, 2017; Maljkovic \& Basic, 2020). Secure heat supply, mitigation of climate change effects and economic competitiveness can be improved by coping with the problem of low energy efficiency of conventional district heating systems (Ziemele, Gravelsins, Blumberga, \& Blumberga, 2017). For that purpose, district heating should be considered not only as a technology that achieves better economic and technological performances, but also to lower the pollution (Wang, Duanmu, Lahdelma, \& Li, 2018). District heating is recognized as an efficient technology for achieving climate goals and reducing pollution (Hansen, Gudmundsson, \& Detlefsen, 2019). It represents the answer to the ever-raising issue of the use of clean energy sources for heat supply.
Pakere \& Blumberga (2020) report several advantages and disadvantages of using centralized district heating. Advantages are seen in the possibility to choose the heat source, higher efficiency, decrease in primary energy consumption, reduction of greenhouse gas emissions etc., while identified disadvantages are higher heat transmission losses, high investment costs, and employing personnel with high technical skills.

District heating has evolved over four generations (Mazhar, Liu, \& Shukla, 2018). District heating systems using renewable energy sources are the $4^{\text {th }}$ generation systems (Ziemele, Pakere, \& Blumberga, 2016). They represent the future development of sustainable heat supply with zero pollution (Pakere \& Blumberga, 2020). This latest generation of district heating systems is characterized by low temperatures, low distribution losses, the use of sustainable energy sources and high efficiency (Volkova, Mašatin, \& Siirde, 2018). Transformation from the convenient 
to the latest, $4^{\text {th }}$ district heating system has been investigated by several authors (Volkova et al., 2018; Lund, Duic, Østergaard, \& Mathiesen, 2018). Furthermore, to move towards the next generation of the district heating systems, new business models have to be applied that support introduction of new technology, high energy efficiency buildings and increased share of renewable energy sources (Paiho \& Reda, 2016). Many authors study the government's role in the transition towards the $4^{\text {th }}$ generation of district heating systems. In a similar review study, Mazhar et al. (2018) performed comparative analysis of existing district heating systems in several countries and their active policies. The results of the analysis indicate Denmark as a country with modern and best operating district heating network in the world, which indicates high government involvement in legislation and operation. Germany is characterized as the owner of sustainable and advanced district heating network and assertive government involvement. China as a huge economy is seen as the fastest growing network in the world with government involvement in reducing carbon footprint. District heating systems in Poland, China and USA are highly dependent on government regulation of sustainable development of the existing systems by introducing renewable energy sources to reduce carbon dioxide footprint. Transition process is complex and depends on many factors that include innovative technology and government regulation (Khabdullin, Khabdullina, Khabdullina, Lauka, \& Blumberga, 2017). The overall goal of the transition is to introduce district heating systems that are flexible and integral part of the future smart energy system $(\mathrm{Li}$ \& Nord, 2018).

The overall goal of this research is to investigate the possible directions for strategic development of a local district heating plant in the city of Bor, located in Eastern Serbia. Development strategies are constructed using elements from the SWOT analysis and prioritized using multi-criteria decision-making methods. The paper consists of five sections. Section 1 contains brief literature review of the applied methodology in the recent publications regarding strategic development of district heating systems. Section 2 presents detailed theoretical background and computational procedure for applied methods, including SWOT analysis, analytic hierarchy process and fuzzy analytic hierarchy process. Strategies that are used for prioritization are developed in Section 3. Research results are reported in the Section 4. The district heating plant will not be discussed in this paper since it was a subject of a previous research, only the outcome of the SWOT analysis would be presented in order to better understand the research problem. Finally, research conclusion is presented in Section 5. To sum up, main contributions of this research are analysing the challenges of the district heat supply in plants and highlighting the important problems. In addition, decision model that is constructed for providing support in developing strategic management can be used in other district heating plants in Serbia. The model is adaptive and allows modification to the actual situation in individual plants.

\section{Methodology}

Proposed methodological framework for this research considered the use of the SWOT analysis that is proven as an effective tool for gathering valuable internal and external data. Then, TOWS analysis is used for forming strategies on the basis of strengths, weaknesses, opportunities and threats. The outcome of SWOT and TOWS tolls served for forming a hybrid model with the Analytic Hierarchy Process (AHP) that is a multicriteria decision-making method. Furthermore, this hybrid model was introduced in its fuzzy environment for providing precise research results.

Multi-criteria decision-making methods have been applied in energy field for solving numerous challenges, and examples of those researches are given in the following part. Fuzzy AHP methodology has been used for solving energy problems regarding the selection of the most appropriate renewable energy source (Kaya \& Kahraman, 2010). The advantage of employing fuzzy environment is preference to lower the uncertainty of information and manage with incomplete data (Wang et al., 2018). Wang et al. (2018) employed fuzzy MCDM methodology to provide the support to decision-making process in planning and designing district heating system. Their study takes in consideration several energetic, economic, technological and environmental criteria. The outcome of their study highlights the economic and energy issues as more influential than technology and environment. In 2018 authors (Ligus \& Peternek, 2018) used fuzzy AHP and fuzzy TOPSIS to prioritize low-emission energy technologies using social, economic and environmental criteria. The 
results of the study indicate on decision-making model that prioritize renewable energy as the most suitable low-emission technology choice.

\subsection{SWOT analysis}

SWOT analysis represents an often-used strategic tool for collecting data about internal and external factors and it usually refers to a company (Solangi, Tan, Mirjat, \& Ali, 2019). Its abbreviation serves to denote strengths (S), weaknesses (W), opportunities (O) and threats (T) where $\mathrm{S}$ and $\mathrm{W}$ elements are recognized as internal factors, while $\mathrm{O}$ and $\mathrm{T}$ elements are recognized as external factors (Wang, $\mathrm{Xu}, \&$ Solangi, 2020). The strategies are generated by combining elements SO, WO, ST and WT. The major limitation of the SWOT lies in its outcome that is only qualitative nature and for further use of the SWOT results; they have to be quantified into numerical values (Tavana, Zareinejad, Di Caprio, \& Kaviani, 2016). Therefore, the proposed methodology includes AHP method that quantifies the importance of the qualitative SWOT elements, with the help of the pairwise comparison matrixes, into numerical priority weights to avoid this problem.

\subsection{AHP method}

Analytic hierarchy process method is among the most used multi-criteria decision-making methodology because it is convenient to use, performs simple calculation procedure and provides the possibility of application to group decision-making problems (Mastrocinque, Ramírez, Honrubia-Escribano, \& Pham, 2020). It is frequently employed for solving unstructured problems that emerge in different areas such as health (Büyüközkan, Mukul, \& Kongar, 2020), transportation (Bouraima, Qiu, Yusupov, \& Ndjegwes, 2020), energy (Gottfried, De Clercq, Blair, Weng, \& Wang, 2018), and other. It is introducing human intellect in evaluating priority of alternatives that are set as solutions for a considered decision-making problem (Beşikçi, Kececi, Arslan, \& Turan, 2016). The advantage of the AHP method can be found in breaking the complexity of decision-making process by structuring the problem in its hierarchy on various levels, thus making it easier for decision makers to judge their preferences (Salvia, Brandli, Leal Filho, \& Kalil, 2019). With the help of the pairwise comparison, the priority weights of all structural elements are being evaluated. The computational procedure for calculating criteria priority weights in the AHP method was introduced by Saaty (1980) and it can be described by using the following three steps.

Step 1. Construct a pairwise comparison matrix. For a decision-making problem that contains $n$ criteria, the process of determining the criteria weights starts by forming a reciprocal square matrix size $n \times n$ (Si et al., 2020).

Saaty's scale is used to implement the AHP method, which is expressed in numerical values from 1 to 9 (Saaty, 2008). To implement the fuzzy AHP method, it is necessary to use triangular fuzzy numbers (TFNs) whose numerical values range from $\tilde{1}$ to $\%$.

Step 2. Calculate the criteria priority weights. The arithmetic mean over the normalized columns method is used to determine the criteria weight.

Step 3: Check the consistency of the pairwise comparison. The most important step in performing pairwise comparison is to check the pairwise comparison consistency. The data about pairwise comparison consistency shows that decision makers are able to express its preferences of one criterion over the other and to understand the applied methodology. The decision about acceptability of the performed pairwise comparisons is made on the results of the Consistency ratio $(C R)$. Pairwise comparisons have to be accepted if the $C R$ is less than or equal to the threshold $10 \%$ ( $\mathrm{Si}$ et al., 2020). If that is not the case, comparisons are rejected and it should be re-evaluated by experts.

To compute the Consistency ratio, the following procedure can be used (Si et al., 2020):

Step 3.1: Compute the maximum eigenvalue of the pairwise comparison matrix $A$.

Step 3.2: Compute the Consistency index $\mathrm{CI}$.

Step 3.3: Finally, compute the Consistency ratio $C R$.

For a group decision-making that includes two or more experts $(K)$, the criteria weight of each criterion $w_{j}$ is calculated using the formula for arithmetic mean, or using the geometric mean formula (Khashei-Siuki \& Sharifan, 2020).

\subsection{Fuzzy AHP}

Introducing the fuzzy environment for decisionmaking problems is done to overcome the problem of the decision maker's consistency. Fuzzy set theory is used when there is incomplete knowledge about the decision-making problem 
(Wang et al., 2020). For most of the decision makers, it is hard to perceive the real situation and assess the impact of different criteria. Thus, it makes it difficult to decide which numerical value to appoint to each criteria and alternative. Therefore, uncertainty arises because of those circumstances. The question of the present uncertainty is especially important when the traditional AHP is used to solve ambiguous problems. Fuzzy framework provides solution for this preference problem by using an interval of numerical values so called, triangular fuzzy numbers instead of crisp values that are used in
AHP (Khashei-Siuki \& Sharifan, 2020). For each crisp numerical value used in AHP, there is an assigned interval of values in TFNs that are used in FAHP. Fuzzy numbers value range from 0 to 1 (Wang et al., 2020). FAHP recognizes three different values that describe a fuzzy event (Beşikçi et al., 2016) and they are entitled as low $(l)$, model $(m)$ and upper $(u)$ value, respectively. Their internal relationship is presented as $l_{j} \leq m_{j} \leq$ $u_{j}$, where $l$ is the lowest value, $m$ is the model value and $u$ is the upper value of the expressed preference. Described methodology is illustrated in the following Fig. 1.

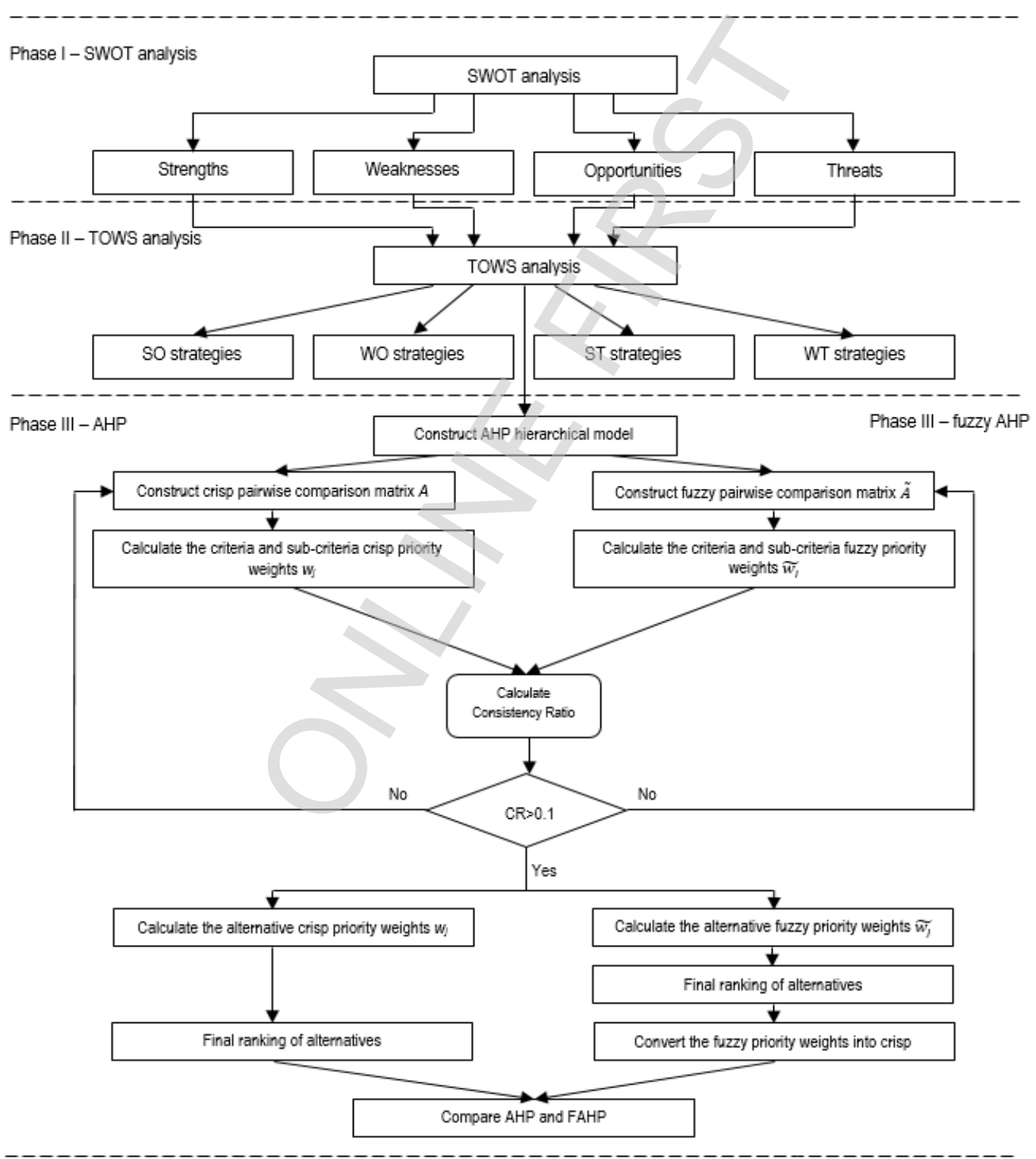

Figure 1 Methodology presentation through research phases Source: the author 


\section{Development of alternatives for strategic management}

In the process of developing strategies aimed at improving the operation of the district heating plant, SWOT analysis has been employed which was adopted from a previous research (Veličkovska, 2019). In that paper, the strengths, weaknesses, opportunities and threats of the district heating plant were identified and described in details. The presented SWOT analysis consists of 24 elements. Internal factors include 4 elements that were identified as strengths $\left(\mathrm{S}_{1}-\mathrm{S}_{4}\right)$ and 7 elements that were identified as weaknesses $\left(\mathrm{W}_{1}-\mathrm{W}_{7}\right)$. External factors include opportunities that incorporate 6 elements $\left(\mathrm{O}_{1}-\mathrm{O}_{7}\right)$, while threats consist of 7 elements $\left(\mathrm{T}_{1}-\mathrm{T}_{7}\right)$. TOWS analysis was adopted in order to obtain alternatives for strategic development of the plant. TOWS analysis is used to construct strategies based on the results of the SWOT analysis. The formulated strategies serve to maximize strengths and opportunities of the plant while at the same time minimize possible weaknesses and threats (Gottfried et al., 2018). TOWS matrix showed in the Table 1 consists of seven strategies. The strategies were generated during the high quality discussion with the interviewed experts.

SO strategies. By relying on the strengths of the company and using the opportunities that emerge in the environment, SO strategies were obtained from the positive elements of the SWOT matrix. They consist of the $\mathrm{SO}_{1}$ strategy - transition to the renewable energy sources and the $\mathrm{SO}_{2}$ strategy finding a strategic partner.

Strategy $\mathrm{SO}_{1}$ was derived from the two elements identified as strengths that are large number of users $\left(\mathrm{S}_{3}\right)$ and expert staff $\left(\mathrm{S}_{4}\right)$. On the other side of the $\mathrm{SO}_{1}$ strategy is the opportunity, which was identified as renewable energy sources $\left(\mathrm{O}_{3}\right)$ that was planned to be utilized. The $\mathrm{SO}_{1}$ strategy is formed to overcome the strict energy policies that are constantly harmonized with the global climate change targets. Since the plant is publicly owned and is the only heating supplier in the city it counts on a large number of heating consumers. The demand for heating supply is high and its position in the heating market is secure. Renewable energy sources are better exploited if district heating systems are larger (Ghafghazi, Sowlati, Sokhansanj, \& Melin, 2010). Besides that, the personnel that is hired in the plant is professional, made up of skilled engineers that are competent for planning and introducing the renewable energy sources as the major energy sources for the heating supply. This strategy is related towards reducing coal use and towards consumers that will become aware regarding their ecological footprint and would like to move to renewable energy sources (Paiho \& Reda, 2016).

Strategy $\mathrm{SO}_{2}$ incorporates the following strengths: satisfactory level of production capacity $\left(\mathrm{S}_{1}\right)$, built district heating system $\left(\mathrm{S}_{2}\right)$ with a large number of users $\left(\mathrm{S}_{3}\right)$ and opportunity found in creating public-private partnership $\left(\mathrm{O}_{5}\right)$. This strategy is seen as a way to use the existing infrastructure and high heating demand to create partnership with private sector and privatize a part of the heating supply in the city. The partnership will provide private investments for recovering the infrastructure that will benefit the quality of the provided heating services and increase the share of satisfied consumers. The general problem regarding this strategy is difficulty in finding adequate strategic partner since investments in district heating systems are high and the payback period is long, which is not convenient for most of the investors that are looking for fast capital turnover (Mazhar et al., 2018).

WO strategies. The next step in creating TOWS matrix is to cross the company's weaknesses and opportunities in order to define WO strategies where strategies $\mathrm{WO}_{1}$ - modernization of technology from $\mathrm{EU}$ funds and $\mathrm{WO}_{2}$ - restoration of the obsolete equipment by crediting belong.

Strategy $\mathrm{WO}_{1}$ includes a variety of weaknesses such as obsolete equipment ( $\left.\mathrm{W}_{1}\right)$, low level of automation $\left(\mathrm{W}_{2}\right)$, many failures $\left(\mathrm{W}_{3}\right)$, lack of financial resources $\left(\mathrm{W}_{4}\right)$, high preparation costs $\left(\mathrm{W}_{6}\right)$, while using the opportunity seen in achieving cooperation with the $\mathrm{EU}\left(\mathrm{O}_{6}\right)$. The plant is reporting many problems with the existing infrastructure and lack of financial resources to cover the modernization of the technology. The high-energy consumption of a district heating plant is often caused by low energy-efficiency operations (Liu et al., 2020). Therefore, strategy $\mathrm{WO}_{1}$ considers establishing the cooperation between the district heating plant as a public plant and the EU by the means of the government. EU is approving assistance as a form of aid for improving energy efficiency through various programs for acceding countries that could be of use in Serbia which energy efficiency score is below the energy goals of the EU countries. Installation of new technology highly depends on the type of energy source that will be used (Ghafghazi et al., 2010).

Strategy WO2 incorporates the same weaknesses as the strategy $\mathrm{WO}_{1}$ but the opportunity that was planned to be used to solve those weaknesses is specialized funds $\left(\mathrm{O}_{2}\right)$. $\mathrm{WO}_{2}$ considers other possibilities of financial flow that is provided by crediting institutions specialized in green energy financing. Those financial services already exist and 
they are an acceptable solution for modernization of the current technology.

ST strategies. Then, by looking at the strengths of the company and threats that appear from the environment, ST strategies was obtained, which include the $\mathrm{ST}_{1}$ strategy - improving institutional measures.

$\mathrm{ST}_{1}$ strategy was constructed using the strengths large number of users $\left(\mathrm{S}_{3}\right)$ and expert staff $\left(\mathrm{S}_{4}\right)$ to solve threats that is defined as reducing the number of users $\left(T_{3}\right)$. Those measures address the problem of large consumer loss. Each year a significant number of consumers disconnects from the district heating network without any financial responsibilities towards the plant. Many of those consumers are living in buildings where heating network is installed so there is a question of passive use of the heating services of former heating consumers. Therefore, the relevant personnel of the plant should construct a detailed policy regarding regulation of consumers' rights and obligations when they use heating services.

WT strategies. The final step in creating the TOWS matrix is crossing the negative elements, weaknesses and threats, in which the $\mathrm{WT}_{1}-$ cooperation with the local government in system renewal and $\mathrm{WT}_{2}$ - introduction of a payment by consumption system strategies were generated.

Strategy $\mathrm{WT}_{1}$ incorporates weaknesses of the company such as obsolete equipment $\left(\mathrm{W}_{1}\right)$, low level of automation $\left(\mathrm{W}_{2}\right)$, many failures $\left(\mathrm{W}_{3}\right)$, lack of financial resources $\left(\mathrm{W}_{4}\right)$, high preparation costs (W6) and responds to the identified threats that are reducing the number of users $\left(\mathrm{T}_{3}\right)$ change of legislation $\left(\mathrm{T}_{4}\right)$ lower investment by state $\left(\mathrm{T}_{5}\right)$ climate change $\left(T_{7}\right)$. Since it is a part of public sector, the management of the plant could address to local government for getting aid in renewing the current technology.

The quality of heating services will increase by modernizing the current technology that could prevent further loss of consumers. In addition, the level of energy efficiency of the heating system should improve by installing new heating network that could in return improve the quality of provided services. Moreover, this improvement of energy efficiency means rising awareness of climate change and the effect that use of coal and inadequate insulation produce. However, local municipalities usually do not possess high amount of money that is needed for renewal of the old district heating systems (Mazhar et al., 2018), so the disposable financial resources should be used in improving some part of the system.

Strategy $\mathrm{WT}_{2}$ includes weaknesses obsolete equipment $\left(\mathrm{W}_{1}\right)$, low level of automation $\left(\mathrm{W}_{2}\right)$, many failures $\left(\mathrm{W}_{3}\right)$, lack of financial resources $\left(\mathrm{W}_{4}\right)$, high preparation costs $\left(\mathrm{W}_{6}\right)$ and responds to the threats including increase in energy prices $\left(T_{1}\right)$, reduction of coal use $\left(T_{2}\right)$, reducing the number of users $\left(T_{3}\right)$, lower investment by state $\left(T_{5}\right)$ and climate change $\left(\mathrm{T}_{7}\right)$. Current calculation payment system relies on data about heating area of each consumer, whether from private or public sector, and the price of heating services per square meter. However, this payment system is recognized as inefficient since both consumers and the plant are dissatisfied with the outcome. Consumers stress the fact that they are paying more than needed, while plant highlights that they are using more coal for less financial compensation. The solution to this problem is seen in constructing an effective payment system which could report about the quantity of heating energy that is consumed by each user. This win-win strategy would result in saving extra financial resources since the plant will charge their heating services according to the demand and the consumers would be able to control their heating demand as needed.

The formation of the hierarchical model is the initial step in the implementation process of the AHP methodology. The model presented in this study consists of four hierarchical layers. The first and the highest layer denotes the goal of the research expressed as finding the best strategy for improving the operation of the district heating plant. This goal is evaluated through the strengths, weaknesses, opportunities and threats of the company expressed in the SWOT analysis. SWOT elements in the model represent the lower layer in the AHP hierarchy and indicate the criteria according to which the decision on choosing the best strategy is made. The SWOT criteria are divided into a number of sub-criteria within each of four SWOT groups. These subcriteria form the third hierarchical layer of the AHP model. 
Table 1 TOWS matrix for generating strategies for strategic management of the district heating plant

\begin{tabular}{|c|c|c|c|}
\hline & & \multicolumn{2}{|c|}{ INTERNAL } \\
\hline & & Strengths (S) & Weaknesses (W) \\
\hline & & $\begin{array}{l}\mathrm{S}_{1} \text { A satisfactory level of production } \\
\text { capacity }\end{array}$ & $W_{1}$ Obsolete Equipment \\
\hline & & $\mathrm{S}_{2}$ Built district heating system & $W_{2}$ Low level of automation \\
\hline & & $\mathrm{S}_{3}$ Large number of users & $\mathrm{W}_{3}$ Many failures \\
\hline & & $\mathrm{S}_{4}$ Expert staff & $W_{4}$ Lack of financial resources \\
\hline & & & $W_{5}$ Inadequate maintenance system \\
\hline & & & $W_{6}$ High preparation costs \\
\hline & & & $\mathrm{W}_{7}$ Use of non-renewable energy sources \\
\hline \multirow{15}{*}{ 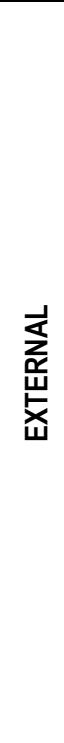 } & Opportunities (O) & SO strategies & WO strategies \\
\hline & $\mathrm{O}_{1}$ Heating price regulation & $\begin{array}{l}\mathrm{SO}_{1} \text { Transition to the renewable } \\
\text { energy sources }\end{array}$ & $\begin{array}{l}\text { WO } 1 \text { Modernization of technology from the } \\
\text { EU funds }\end{array}$ \\
\hline & $\mathrm{O}_{2}$ Specialized funds & $\mathrm{SO}_{2}$ Finding a strategic partner & $\begin{array}{l}\mathrm{WO}_{2} \text { Restoration of the obsolete } \\
\text { equipment by taking loans }\end{array}$ \\
\hline & $\mathrm{O}_{3}$ Renewable energy sources & & 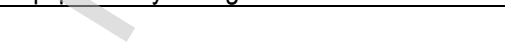 \\
\hline & $\mathrm{O}_{4}$ Gasification & & \\
\hline & $\mathrm{O}_{5}$ Public-Private Partnership & & \\
\hline & $\mathrm{O}_{6}$ Cooperation with the $\mathrm{EU}$ & & \\
\hline & Threats $(T)$ & ST strategies & WT strategies \\
\hline & $\mathrm{T}_{1}$ Increase in energy prices & $\mathrm{ST}_{1}$ Improving institutional measures & $\begin{array}{l}\text { WT }_{1} \text { Cooperation with the local } \\
\text { government in system renewal }\end{array}$ \\
\hline & $\mathrm{T}_{2}$ Reduction of coal use & & $\begin{array}{l}\mathrm{WT}_{2} \text { Introduction of a payment by } \\
\text { consumption system }\end{array}$ \\
\hline & $T_{3}$ Reducing the number of users & & \\
\hline & $\mathrm{T}_{4}$ Change of legislation & & \\
\hline & $T_{5}$ Lower investment by state & & \\
\hline & $\begin{array}{l}\mathrm{T}_{6} \text { Outflow of skilled labour and } \\
\text { unemployment }\end{array}$ & & \\
\hline & $T_{7}$ Climate change & & \\
\hline
\end{tabular}

The fourth hierarchical layer is expressed in the of the district heating plant. The form of alternatives that are, in this case, given in interdependencies of the hierarchical layers are the form of strategies for improving the operation illustrated in Fig. 2 below.

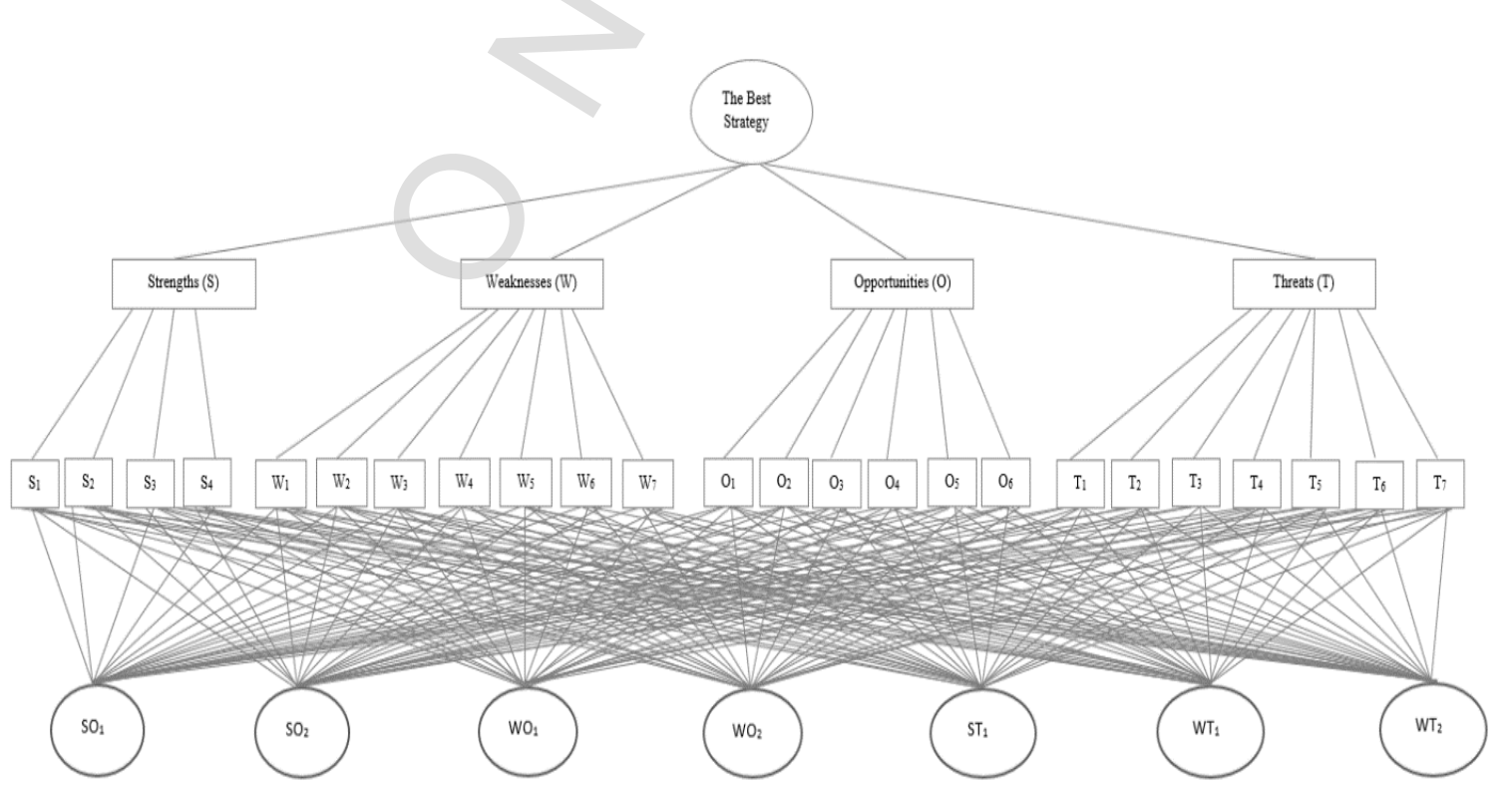

Figure 2 The structure of the AHP hierarchical model Source: the author 


\section{Results}

The first step in implementing AHP methodology is to calculate the priority weights of the strengths, weaknesses, opportunities and threats that were identified in the previous research. Experts from the district heating plant, who are very well informed about the current situation in the plant, estimated the weights of criteria, sub-criteria and alternatives. Scale for estimating the weights of criteria and sub-criteria is Saaty's. The results of the pairwise comparison suggest strong impact of the criterion weaknesses $(0.445)$ on the final goal of the prioritization. In other words, weaknesses of the company are the criterion that, to the greatest extent, influence on the selection of the most appropriate strategy that will be implemented first. The obtained result was expected since the plant has suffered from inadequate investments in modern equipment and appropriate infrastructure for years. Reason for this is lack of own financial resources for realizing such great projects. The way in which the plant solves those internal problems determines how fast it will be developed. The second ranked criterion is opportunities $(0.283)$ that are provided in the company's surrounding. Its high value implies that there are various directions for developing the plant that could be used in the form of introducing renewable energy for the district heating needs, regulating current heating prices, starting cooperation with the EU and other identified chances. Threats $(0.165)$ are ranked as the third criterion in the pairwise comparison matrix. Threats reflect the unstable market and changing environment. Examples of those threats are possible changes of the government regulative regarding climate change and non-renewable energy sources. Another rising problem is losing a valuable number of current users which will reduce the demand for the district heating services. The fourth ranked criterion in the pairwise matrix represent strengths (0.107) that are manifested as high number of users, employed engineers that run the operating process and sufficiently good production capacity. Well-built district heating network is also a strength of the plant but in the same way is a weakness since the network covers $90 \%$ of the city but is in poor condition with many failures.

The next step is to generate pairwise comparison matrices for all sub-criteria that are presented as the third level in the AHP structural model. In total, four comparison matrices were generated, for each criterion, and experts evaluated their elements quantitatively. The results of the comparisons are showed in Table 2.

Empirical evidence of the comparison shows the reciprocal importance of sub-criteria on the local level. Then, global importance of subcriteria are calculated by multiplying the local importance of the each sub-criterion with the importance of the relevant criterion. By observing the results of the local importance of the subcriteria, it can be seen that the most influencing sub-criteria of each group criteria are arranged descending as $\mathrm{S}_{3}>\mathrm{O}_{1}>\mathrm{W}_{4}>\mathrm{T}_{3}$. After adding the value of the criteria to the value of the sub-criteria the same local sub-criteria remain as the most important but their values have adjusted causing change in their descending sequence to $\mathrm{W}_{4}>\mathrm{O}_{1}>\mathrm{S}_{3}, \mathrm{~T}_{3}$. Sub-criterion $\mathrm{S}_{3}$ and $\mathrm{T}_{3}$ share the same weight (0.055). Comparatively with calculating pairwise matrix, the consistency ratio was determined for all criteria and sub-criteria matrices. CR for criteria is reported in Table 2, where it can be seen that it equals less than $10 \%$ which is the threshold for achieving consistency. $\mathrm{CR}$ for sub-criteria was also calculated and it equals less than $10 \%$ for all pairwise comparison matrices.

After calculating the importance of subcriteria, the importance of each sub-criterion towards alternatives that are demonstrated in the Fig. 2 was considered. Using a quantitative scale, experts evaluated the relationship among all alternatives with respect to the perceived subcriteria. According to the sub-criteria, alternatives that were highly rated are $\mathrm{SO}_{1}, \mathrm{WO}_{2}$ and $\mathrm{WT}_{2}$. The last step in implementing AHP is performing final prioritization of alternatives with respect to the primary goal. The results of the final prioritization are compared with the results of the FAHP methodology.

Further prioritization of the employed alternatives is done using the AHP methodology in the fuzzy environment and the results are presented in the following part of the research. The basic step in applying FAHP is calculating priority weights of criteria that were presented in the Fig. 2. The difference related to the previously applied AHP can be found in the use of triangular fuzzy number (FTN). 
Table 2 Results of the pairwise comparison of the each SWOT criterion and sub-criterion using the AHP method

\begin{tabular}{|c|c|c|c|c|}
\hline $\begin{array}{lll}\text { SWOT } & \text { groups } \quad- \\
\text { criterion } & & \\
\end{array}$ & $\begin{array}{l}\text { The importance of } \\
\text { the SWOT criterion }\end{array}$ & $\begin{array}{l}\text { SWOT sub- } \\
\text { criterion }\end{array}$ & $\begin{array}{l}\text { Local importance of } \\
\text { SWOT sub-criterion }\end{array}$ & $\begin{array}{l}\text { Global importance of SWOT sub- } \\
\text { criterion }\end{array}$ \\
\hline \multirow{4}{*}{$\begin{array}{l}\text { Strengths }(S) \\
\text { CR }=0.05\end{array}$} & \multirow[t]{4}{*}{0.107} & $S_{1}$ & 0.219 & 0.023 \\
\hline & & $\mathrm{S}_{2}$ & 0.177 & 0.019 \\
\hline & & $\mathrm{S}_{3}$ & 0.516 & 0.055 \\
\hline & & $\mathrm{S}_{4}$ & 0.088 & 0.009 \\
\hline \multirow{7}{*}{$\begin{array}{l}\text { Weaknesses }(\mathrm{W}) \\
\mathrm{CR}=0.08\end{array}$} & \multirow[t]{7}{*}{0.445} & $W_{1}$ & 0.179 & 0.080 \\
\hline & & $\mathrm{W}_{2}$ & 0.157 & 0.070 \\
\hline & & $W_{3}$ & 0.125 & 0.056 \\
\hline & & $W_{4}$ & 0.337 & 0.150 \\
\hline & & $W_{5}$ & 0.089 & 0.039 \\
\hline & & $W_{6}$ & 0.068 & 0.030 \\
\hline & & $W_{7}$ & 0.044 & 0.020 \\
\hline \multirow{6}{*}{$\begin{array}{l}\text { Opportunities }(0) \\
\mathrm{CR}=0.07\end{array}$} & \multirow[t]{6}{*}{0.283} & $\mathrm{O}_{1}$ & 0.366 & 0.104 \\
\hline & & $\mathrm{O}_{2}$ & 0.200 & 0.057 \\
\hline & & $\mathrm{O}_{3}$ & 0.162 & 0.046 \\
\hline & & $\mathrm{O}_{4}$ & 0.080 & 0.023 \\
\hline & & $\mathrm{O}_{5}$ & 0.052 & 0.015 \\
\hline & & $\mathrm{O}_{6}$ & 0.140 & 0.040 \\
\hline \multirow{7}{*}{$\begin{array}{l}\text { Threats }(T) \\
C R=0.09\end{array}$} & \multirow[t]{7}{*}{0.165} & $\mathrm{~T}_{1}$ & 0.129 & 0.021 \\
\hline & & $\mathrm{T}_{2}$ & 0.201 & 0.033 \\
\hline & & $\mathrm{T}_{3}$ & 0.331 & 0.055 \\
\hline & & $\mathrm{T}_{4}$ & $0 . \overline{159}$ & 0.026 \\
\hline & & $T_{5}$ & 0.089 & 0.015 \\
\hline & & $T_{6}$ & 0.052 & 0.009 \\
\hline & & $\mathrm{T}_{7}$ & 0.040 & 0.007 \\
\hline
\end{tabular}

FTNs allow deeper analysis because the alternative, followed by opportunities, threats and calculation procedure is done for lower $(l)$, middle strengths successively.

$(m)$ and upper $(u)$ priority weights. Pairwise After computing the fuzzy priority weights of comparison matrix for criteria presented in the the criteria, the next step is to calculate fuzzy Table 3 highlights weaknesses as the most local and global importance of sub-criteria. important criterion in choosing the best

Table 3 Results of the pairwise comparison of the each SWOT criterion and sub-criterion using the FAHP method

\begin{tabular}{|c|c|c|c|c|}
\hline $\begin{array}{l}\text { SWOT groups - } \\
\text { criteria }\end{array}$ & $\begin{array}{l}\text { The importance of the } \\
\text { SWOT criteria }\end{array}$ & $\begin{array}{l}\text { SWOT sub- } \\
\text { criterion }\end{array}$ & $\begin{array}{l}\text { Local importance of SWOT } \\
\text { sub-criterion }\end{array}$ & $\begin{array}{l}\text { Global importance of } \\
\text { SWOT sub-criterion }\end{array}$ \\
\hline \multirow[t]{4}{*}{ Strengths (S) } & \multirow[t]{4}{*}{$(0.117,0.098,0.112)$} & $\mathrm{S}_{1}$ & $(0.192,0.218,0.229)$ & $(0.023,0.021,0.026)$ \\
\hline & & $\mathrm{S}_{2}$ & $(0.173,0.170,0.187)$ & $(0.020,0.017,0.021)$ \\
\hline & & $\mathrm{S}_{3}$ & $(0.542,0.525,0.491)$ & $(0.064,0.052,0.055)$ \\
\hline & & $\mathrm{S}_{4}$ & $(0.093,0.087,0.093)$ & $(0.011,0.009,0.010)$ \\
\hline \multirow[t]{7}{*}{ Weaknesses (W) } & \multirow[t]{7}{*}{$(0.437,0.449,0.417)$} & $W_{1}$ & $(0.172,0.190,0.192)$ & $(0.075,0.085,0.080)$ \\
\hline & & $W_{2}$ & $(0.157,0.159,0.161)$ & $(0.069,0.071,0.067)$ \\
\hline & & $W_{3}$ & $(0.122,0.123,0.132)$ & $(0.053,0.055,0.055)$ \\
\hline & & $W_{4}$ & $(0.350,0.336,0.311)$ & $(0.153,0.151,0.130)$ \\
\hline & & $W_{5}$ & $(0.085,0.085,0.091)$ & $(0.037,0.038,0.038)$ \\
\hline & & $W_{6}$ & $(0.070,0.067,0.074)$ & $(0.031,0.030,0.031)$ \\
\hline & & $W_{7}$ & $(0.045,0.040,0.040)$ & $(0.020,0.018,0.017)$ \\
\hline \multirow[t]{6}{*}{ Opportunities (0) } & \multirow[t]{6}{*}{$(0.279,0.287,0.295)$} & $\mathrm{O}_{1}$ & $(0.365,0.360,0.337)$ & $(0.102,0.103,0.099)$ \\
\hline & & $\mathrm{O}_{2}$ & $(0.192,0.208,0.208)$ & $(0.054,0.060,0.062)$ \\
\hline & & $\mathrm{O}_{3}$ & $(0.160,0.165,0.174)$ & $(0.045,0.047,0.051)$ \\
\hline & & $\mathrm{O}_{4}$ & $(0.085,0.079,0.081)$ & $(0.024,0.023,0.024)$ \\
\hline & & $\mathrm{O}_{5}$ & $(0.056,0.050,0.050)$ & $(0.016,0.014,0.015)$ \\
\hline & & $\mathrm{O}_{6}$ & $(0.142,0.137,0.150)$ & $(0.040,0.039,0.044)$ \\
\hline \multirow[t]{3}{*}{ Threats (T) } & \multirow[t]{3}{*}{$(0.166,0.166,0.175)$} & $\mathrm{T}_{1}$ & $(0.124,0.121,0.123)$ & $(0.021,0.020,0.022)$ \\
\hline & & $\mathrm{T}_{2}$ & $(0.203,0.214,0.214)$ & $(0.034,0.035,0.038)$ \\
\hline & & $T_{3}$ & $(0.339,0.336,0.320)$ & $(0.056,0.056,0.056)$ \\
\hline
\end{tabular}




\begin{tabular}{l|l|l|l|l|}
\hline \multirow{5}{*}{} & $\mathrm{T}_{4}$ & $(0.159,0.161,0.167)$ & $(0.026,0.027,0.029)$ \\
\cline { 2 - 4 } & $\mathrm{T}_{5}$ & $(0.084,0.081,0.084)$ & $(0.014,0.013,0.015)$ \\
\cline { 2 - 4 } & $\mathrm{T}_{6}$ & $(0.050,0.050,0.052)$ & $(0.008,0.008,0.009)$ \\
\cline { 2 - 4 } & $\mathrm{T}_{7}$ & $(0.040,0.037,0.039)$ & $(0.007,0.006,0.007)$ \\
\hline
\end{tabular}

Source: the author

The pairwise comparison matrix was evaluated with TFN values. The results of local and global pairwise comparisons, presented in Table 3, identify sub-criteria $\mathrm{S}_{3}, \mathrm{~W}_{4}, \mathrm{O}_{1}$ and $\mathrm{T}_{3}$ as the most influencing for alternatives prioritization. Furthermore, FAHP method considers fuzzy pairwise comparisons among alternatives in relation to the sub-criteria. The final step in the AHP and FAHP methodology is to perform the prioritization of the proposed alternatives in order to select the best alternative for reaching the strategic management of the district heating plant. For that purpose, fuzzy priority weights of the alternatives were converted into crisp values so that the results of AHP and FAHP could be compared. The results of the prioritization are presented in the Table 4 for both AHP and FAHP methods. AHP method ranked alternative $\mathrm{WT}_{2}$ $(0.183)$ as the best alternative with respect to the goal of the prioritization. The second ranked is the alternative $\mathrm{WO}_{1}(0.178)$, while the third ranked is the alternative $\mathrm{WO}_{2}(0.169)$. Ranking performed using the FAHP method provides oscillations in the results in comparison with the AHP. The most preferred alternative is the alternative $\mathrm{WO}_{2}$ (0.219), the second ranked alternative is the alternative $\mathrm{WT}_{2}(0.194)$ and the third ranked is the alternative $\mathrm{WO}_{1}(0.189)$. Other alternatives $\mathrm{ST}_{1}$, $\mathrm{WT}_{1}, \mathrm{SO}_{1}$, and $\mathrm{SO}_{2}$ are ranked as the $4^{\text {th }}, 5^{\text {th }}, 6^{\text {th }}$ and $7^{\text {th }}$ in both cases, AHP and FAHP. Empirical evidence suggest that alternatives emerged from the weaknesses of the district heating plant and threats and opportunities that come from the external sources need to be implemented with high priority.

Table 4 Final prioritization of alternatives for improving the operation of the district heating power plant using the AHP and fuzzy AHP method

\begin{tabular}{l|l|l|l|l}
\hline Alternatives & AHP & Fuzzy AHP \\
\hline & Weight (wj) & Rank & $\begin{array}{l}\text { Weight } \\
(w j)\end{array}$ & Rank \\
\hline $\mathrm{SO}_{1}$ & 0.132 & 6 & 0.136 & 6 \\
\hline $\mathrm{SO}_{2}$ & 0.060 & 7 & 0.065 & 7 \\
\hline $\mathrm{WO}_{1}$ & 0.178 & 2 & 0.189 & 3 \\
\hline $\mathrm{WO}_{2}$ & 0.169 & 3 & 0.219 & 1 \\
\hline $\mathrm{ST}_{1}$ & 0.144 & 4 & 0.159 & 4 \\
\hline $\mathrm{WT}_{1}$ & 0.134 & 5 & 0.137 & 5 \\
\hline $\mathrm{WT}_{2}$ & 0.183 & 1 & 0.194 & 2 \\
\hline & \multicolumn{4}{|c}{ Source: the author }
\end{tabular}

The sequence of their implementation is presented in the Table 4 in the ranking column.
Priority weights for the alternatives $\mathrm{WT}_{2}$ and $\mathrm{WO}_{1}$ have approximate values so realizing them simultaneously should be considered. The same conclusion was reached for alternatives $\mathrm{WT}_{1}$ and $\mathrm{SO}_{1}$. It has to be highlighted that moving from a previous to the next strategy depends on the effects that current strategy is achieving on the plant's operation.

Fuzzy environment of the AHP methodology emphasises the strategy to restore the old equipment of the plant by using financial services from the bank. This strategy is ranked the first, since it is evident the problem of the outdated technology and following infrastructure that is needed for the heating supply. Since the lack of financial resources is another weakness of the plant, the capital for this investment needs to be acquired from external financing sources. Experts evaluated this strategy as the initial step in developing strategic management in the district heating plant. Most of the identified weaknesses will be solved by investing in technology and infrastructure. New technology would provide higher level of process automation and reduce the number of failures that are frequent in the heating season. The problem of frequent failures of the heating supply is causing many other challenges since all repairs take up financial and human resources. Therefore, the maintenance process is extended and production costs are increased due to the heating system failure and longer preparation time.

After implementing the strategy, the first ranked strategy to renew the technology and infrastructure, the next step is to change the collection policy of the district heating plant. This represents a significant responsibility for the management of the plant, since the current payment system is described as inadequate and unsustainable. The general problem is seen in the higher heat supply and lower payment by consumers, resulting in the deficit in the disposable financial resources. The proposed idea is to change from collection by heated area measured in square meters, to the collection by the provided heating temperature. This could result in large energy savings since all consumers will use the heating services only in the area that they utilize and set the temperature according to 
their needs. In this way, consumers will have control over their consumption.

The new payment system will provide benefits for both, the heating supplier and the heating consumer. Since the local heating system covers $90 \%$ of total heat consumers, the district heating network is complex and long. Therefore, financial resources from the bank cannot be enough to solve all network problems at once because it would mean very high debt and insufficient resources to pay it off. So, the next strategy that would be implemented is the strategy relying on modernization of technology from the EU funds. As a country in the process of accession to the EU Serbia has achieved cooperation with the EU and has few energy projects that aim towards improving energy efficiency. The management of the district heating plant that is a part of the public sector in Serbia should plan to negotiate with the government to create the possibility to access the funds allocated for improving energy efficiency. These financial resources would be used to further modernize the technology needed for the heating supply.

The next problem that needs to be handled is the problem of losing consumers. Strategy that is constructed to solve this problem is the strategy regarding improvement of institutional measures. The plant is facing a big challenge that is lowering the number of heat consumers. The reasons for this unfavourable number are numerous and can be found in dissatisfaction of consumers arising from low quality services. Low quality of heating services is reported in periods of high failures of the heating network. Hansen et al. (2019) investigated the problem of heat loss in the heat distribution and in the households. Their study suggests that district heating network is competitive in the area where there is high heat demand and high density, but do not recommend the use of district heating network in low density areas where the demand for heat is low. The majority of the former heat consumers in the investigated area are living in buildings where district heating network exists and are still using the services from the plant in a passive form without paying any financial compensation. In addition, disconnection from the district heating grid is free of charge. Therefore, the experts from the plant should revise their consumer's behaviour policies and take into account the reported problems to find the right institutional measures in response.
Moreover, the management of the district heating plant should initiate cooperation with the local government to renew the district heating system. The district heating plant is the only one responsible for the heating season in the city so collaboration between the plant and the municipality could result in developing the infrastructure needed for improved heating supply. The outcome of this collaboration would be secured heating supply of the local population.

When all previous strategies are realized, the management of the plant could consider transition from coal as fuel for the district heating to renewable energy resources. This strategy is very attractive due to the rising climate problems and unsustainable resource use. Serbia owns coal mining companies and the use of coal is secured for years but the national energy policies report the need for increasing the share of renewables in the heating supply. Therefore, this strategy is in accordance with the energy goals of the country.

The least preferred strategy is finding a strategic partner. The experts from the plant evaluated this strategy as the last choice to improve the strategic management. If the management of the plant could improve the current technology and allocate financial resources for further development, there would be no need for partnership because the plant would have sustainable business results.

\section{Conclusion}

This work aimed to propose an integrated SWOTAHP-FAHP framework for providing support in the decision-making process for solving problems related to efficient heat supply. The example of a district heating plant that was the subject of the research served to implement MCDM methods to reveal the leading challenges in the operating process, detect the most important opportunities provided in the external environment and notice the biggest threats. The main reason for employing MCDM methods can be found in the fact that this methodology is always a good choice when the decision has to be made in a complex environment. In the research, multi-criteria decision-making was used to guide the selection of the best strategy to improve the operation of the local district heating plant. So, before making any strategic decision regarding the plant it is necessary to perceive current inner situation in the plant. Since the plant is providing its services to the local population, public and private sector, the impact that outer environment is making on the 
operating performances of the plant has to be considered. Therefore, SWOT is seen as a great tool for analysing internal and external environment of this energy system. The constructed hybrid model is seen as the first step in providing efficient heat supply in the district heating plant.

The main phases of this research are summarized in the following part.

As mentioned above, conducting the SWOT analysis represents the first phase in the research study. It was employed to gather data about the current situation in the internal and external environment of the district heating plant. Acquiring those data is of great importance because they provide many useful information for the decision makers and clarify their attitude towards the decision problem. The outcome of the SWOT analysis was used to construct TOWS matrix that represents the second phase in the research study. In this case, TOWS matrix was formed by pairing $\mathrm{SO}, \mathrm{WO}, \mathrm{ST}$ and WT elements that are integral parts of the SWOT analysis. The empirical evidence suggest seven alternatives that emerge as the result of combining elements in the TOWS matrix. All seven alternatives were interpreted in the form of strategies that are going to be used to solve the most important problems in the plant and to improve its operation. Described strategies cope with the most important question for the future of the plant such as the transition to the use of renewable energy sources instead of coal. This issue is related to the management of the natural resources and its rational use. Another burning question in this plant is the problem of the outdated technology and supporting infrastructure that cause many related issues in the operating process. The problem with the poor technology development in the plant is the reason for majority of the identified weaknesses. The SWOT analysis revealed another important difficulty for the plant that is further developing of customer and service policy since this area is missing the exact regulation of the customer's behaviour. Finally, the last discussed problem that is highly important is introducing the concept of payment by consumption system. This system allows the customers to control their consumption and optimize the heating temperature. It is already implemented in the EU and it should be implemented in the plant since it will make the balance between the input resources in the plant and outcomes, providing a large share of satisfied consumers.
The third phase in the research study is to construct a hierarchical model of the decisionmaking problem that is needed for describing the internal connections between criteria, sub-criteria and alternatives to the primary goal. The AHP hierarchical model consists of four levels. The results of the AHP method suggest SWOT criteria weaknesses (W) as the most important criteria for the final prioritization of alternatives, followed by opportunities (O). Furthermore, the outcome of the sub-criteria prioritization highlights $\mathrm{S}_{3}, \mathrm{~W}_{4}$, $\mathrm{O}_{1}$, and $\mathrm{T}_{3}$ as the most influencing sub-criteria on the alternative's selection. Final prioritization of the alternatives revealed alternatives $\mathrm{WT}_{2}, \mathrm{WO}_{1}$, $\mathrm{WO}_{2}$ as highly important for the goal of the prioritization that is to support strategic management in the district heating plant. The fourth phase represents the implementation of AHP method in the fuzzy environment using TFN. FAHP results provide the same highlights as AHP method. Empirical evidence suggest weaknesses (W) as determining criterion for the alternative's prioritization. The most influential criteria are $\mathrm{S}_{3}, \mathrm{~W}_{4}, \mathrm{O}_{1}$, and $\mathrm{T}_{3}$, with variation in the priority weights in comparison with the AHP results. $\mathrm{WO}_{2}, \mathrm{WT}_{2}$ and $\mathrm{WO}_{1}$ are ranged as the top three alternatives with the highest priority weights. Translating TFN values of the priority weights in fuzzy environment into the crisp values it was enabled to compare outcomes of the two methods. Except the change of the priority of top three alternatives, there are no major variations in the results obtained by the AHP and FAHP methods. The proposed strategies should be implemented simultaneously. Considering how effective the previous strategy was, the management should make a decision whether to implement the next strategy or to hold on the current.

The main scientific finding in this paper is recognized in constructing a multi-criteria decision-making model based on SWOT, AHP and fuzzy AHP methods. The value of this model can be found in its implementation across the energy sector in Serbia and other developing countries that are facing similar problems such as lack of financial resources, poor technology development and use of non-renewable energy sources. The model is highly flexible and allows to be adapted to different criteria and alternatives that emerge in heterogeneous decision-making problems. Regarding the future research, the author should consider applying other MCDM 
methods to resolve similar problems that appear in the energy sector.sw

\section{Acknowledgment}

This work was supported by the Serbian Ministry of Education, Science and Technological Development through Mathematical Institute of the Serbian Academy of Sciences and Arts.

\section{References}

Beşikçi, E. B., Kececi, T., Arslan, O., \& Turan, O. (2016). An application of fuzzy-AHP to ship operational energy efficiency measures. Ocean Engineering, 121, 392-402. https://dx.doi.org/10.1016/j.oceaneng.2016.05.031

Bouraima, M. B., Qiu, Y., Yusupov, B., \& Ndjegwes, C. M. (2020). A study on the development strategy of the railway transportation system in the West African Economic and Monetary Union (WAEMU) based on the SWOT/AHP technique. Scientific African, 8, e00388. http://dx.doi.org/10.1016/j.sciaf.2020.e00388

Büyüközkan, G., Mukul, E., \& Kongar, E. (2021). Health tourism strategy selection via SWOT analysis and integrated hesitant fuzzy linguistic AHP-MABAC approach. Socio-Economic Planning Sciences, 74, 100929. https://doi.org/10.1016/j.seps.2020.100929

Ligus, M., \& Peternek, P. (2018). Determination of most suitable low-emission energy technologies development in Poland using integrated fuzzy AHP-TOPSIS method. Energy Procedia, 153, 101-106. https://dx.doi.org/10.1016/j.egypro.2018.10.046

Ghafghazi, S., Sowlati, T., Sokhansanj, S., \& Melin, S. (2010). A multicriteria approach to evaluate district heating system options. Applied energy, 87(4), 11341140. https://dx.doi.org/10.1016/j.apenergy.2009.06.021

Gottfried, O., De Clercq, D., Blair, E., Weng, X., \& Wang, C. (2018). SWOT-AHP-TOWS analysis of private investment behaviour in the Chinese biogas sector. Journal of Cleaner Production, 184, 632-647. https://dx.doi.org/10.1016/j.jclepro.2018.02.173

Hansen, C. H., Gudmundsson, O., \& Detlefsen, N. (2019). Cost efficiency of district heating for low energy buildings of the future. Energy, 177, 77-86. https://dx.doi.org/10.1016/j.energy.2019.04.046

Kaya, T., \& Kahraman, C. (2010). Multicriteria renewable energy planning using an integrated fuzzy VIKOR \& AHP methodology: The case of Istanbul. Energy, 35(6), 2517-2527.

https://dx.doi.org/10.1016/j.energy.2010.02.051

Khabdullin, A., Khabdullina, Z., Khabdullina, G., Lauka, D., \& Blumberga, D. (2017). Demand response analysis methodology in district heating system. Energy Procedia, 128, 539-543. https://dx.doi.org/10.1016/j.egypro.2017.09.004

Khashei-Siuki, A., \& Sharifan, H. (2020). Comparison of AHP and FAHP methods in determining suitable areas for drinking water harvesting in Birjand aquifer. Iran. Groundwater for Sustainable Development, 10, 100328. https://dx.doi.org/10.1016/j.gsd.2019.100328
Kveselis, V., Dzenajavičienè, E. F., \& Masaitis, S. (2017). Analysis of energy development sustainability: The example of the Lithuanian district heating sector. Energy Policy, 100, 227-236. https://dx.doi.org/10.1016/j.enpol.2016.10.019

Li, H., \& Nord, N. (2018). Transition to the 4th generation district heating-possibilities, bottlenecks, and challenges. Energy Procedia, 149, 483-498. https://dx.doi.org/10.1016/j.egypro.2018.08.213

Liu, Y., Hu, X., Luo, X., Zhou, Y., Wang, D., \& Farah, S. (2020). Identifying the most significant input parameters for predicting district heating load using an association rule algorithm. Journal of Cleaner Production, 275, 122984. https://doi.org/10.1016/j.jclepro.2020.122984

Lund, H., Duic, N., Østergaard, P. A., \& Mathiesen, B. V. (2018). Future district heating systems and technologies: On the role of smart energy systems and 4th generation district heating. Energy, 165, 614-619. https://dx.doi.org/10.1016/j.energy.2018.09.115

Maljkovic, D., \& Basic, B. D. (2020). Determination of influential parameters for heat consumption in district heating systems using machine learning. Energy, 201, 117585 https://doi.org/10.1016/j.energy.2020.117585

Mastrocinque, E., Ramírez, F. J., Honrubia-Escribano, A., \& Pham, D. T. (2020). An AHP-based multi-criteria model for sustainable supply chain development in the renewable energy sector. Expert Systems with Applications, 150, 113321.

https://dx.doi.org/10.1016/j.eswa.2020.113321

Mazhar, A. R., Liu, S., \& Shukla, A. (2018). A state of art review on the district heating systems. Renewable and Sustainable Energy Reviews, 96, 420-439. https://dx.doi.org/10.1016/i.rser.2018.08.005

Paiho, S., \& Reda, F. (2016). Towards next generation district heating in Finland. Renewable and Sustainable Energy Reviews, 65, 915-924. https://dx.doi.org/10.1016/j.rser.2016.07.049

Pakere, I., \& Blumberga, D. (2020). Solar power or solar heat: What will upraise the efficiency of district heating? Multi-criteria analyses approach. Energy, 198, 117291. https://doi.org/10.1016/j.energy.2020.117291

Saaty, T. L. (1980). The Analytic Hierarchy Process: Planning, Priority Setting, Resource Allocation. New York: McGraw-Hill.

Saaty, T. L. (2008). Decision making with the analytic hierarchy process. International journal of services sciences, 1(1), 83-98. https://dx.doi.org/10.1504/IJSSCI.2008.017590

Salvia, A. L., Brandli, L. L., Leal Filho, W., \& Kalil, R. M. L. (2019). An analysis of the applications of Analytic Hierarchy Process (AHP) for selection of energy efficiency practices in public lighting in a sample of Brazilian cities. Energy Policy, 132, 854-864. https://dx.doi.org/10.1016/j.enpol.2019.06.021

Si, T., Wang, C., Liu, R., Guo, Y., Yue, S., \& Ren, Y. (2020). Multi-criteria comprehensive energy efficiency assessment based on fuzzy-AHP method: A case study of post-treatment technologies for coal-fired units. Energy, 200, 117533. https://doi.org/10.1016/j.energy.2020.117533 
Solangi, Y. A., Tan, Q., Mirjat, N. H., \& Ali, S. (2019). Evaluating the strategies for sustainable energy planning in Pakistan: An integrated SWOT-AHP and Fuzzy-TOPSIS approach. Journal of Cleaner Production, 236, 117655. https://dx.doi.org/10.1016/j.jclepro.2019.117655

Tavana, M., Zareinejad, M., Di Caprio, D., \& Kaviani, M. A. (2016). An integrated intuitionistic fuzzy AHP and SWOT method for outsourcing reverse logistics. Applied Soft Computing, 40, 544-557. https://dx.doi.org/10.1016/j.asoc.2015.12.005

Veličkovska I. (2019). Application of SWOT Analysis in the Energy sector: A Case Study of a District Heating Plant. In $5^{\text {th }}$ Virtual International Conference on Science (pp. 177-183). Technology and Management in Energy eNergetics.

Volkova, A., Mašatin, V., \& Siirde, A. (2018). Methodology for evaluating the transition process dynamics towards 4th generation district heating networks. Energy, 150, 253-261.

https://dx.doi.org/10.1016/j.energy.2018.02.123

Wang, H., Duanmu, L., Lahdelma, R., \& Li, X. (2018). A fuzzy-grey multicriteria decision making model for district heating system. Applied Thermal Engineering, 128, 1051-1061. https://dx.doi.org/10.1016/j.applthermaleng.2017.08.04 $\underline{8}$

$\triangle$ Correspondence

\section{Ivana Veličkovska}

Mathematical Institute of the Serbian Academy of Sciences and Arts

Kneza Mihaila 36, 11000, Belgrade, Serbia

E-mail: ivana993@turing.mi.sanu.ac.rs
Wang, Y., Xu, L., \& Solangi, Y. A. (2020). Strategic renewable energy resources selection for Pakistan: Based on SWOT-Fuzzy AHP approach. Sustainable Cities and Society, 52, 101861. https://dx.doi.org/10.1016/j.scs.2019.101861

Ziemele, J., Gravelsins, A., Blumberga, A., \& Blumberga, D. (2017). Combining energy efficiency at source and at consumer to reach 4th generation district heating: Economic and system dynamics analysis. Energy, 137, 595-606.

https://dx.doi.org/10.1016/j.energy.2017.04.123

Ziemele, J., Pakere, I., \& Blumberga, D. (2016). The future competitiveness of the non-Emissions Trading Scheme district heating systems in the Baltic States. Applied Energy, 162, 1579-1585.

https://dx.doi.org/10.1016/j.apenergy.2015.05.043 